\title{
Laser Flash Photolysis Study of the Photochemistry of Thioxanthone in Organic Solvents
}

\author{
Janaina F. Rodrigues, ${ }^{a}$ Francisco de Assis da Silva ${ }^{a}$ and José Carlos Netto-Ferreira ${ }^{*, a, b}$ \\ ${ }^{a}$ Departamento de Química, Universidade Federal Rural do Rio de Janeiro, BR $465 \mathrm{~km} 7$, \\ 23970-000 Seropédica-RJ, Brazil \\ ${ }^{b}$ Instituto de Química, Universidade Federal da Bahia, Campus de Ondina, \\ 40170-290 Salvador-BA, Brazil
}

\begin{abstract}
A fotorreatividade do estado excitado triplete de tioxantona (TX) foi investigada empregando a técnica de fotólise por pulso de laser. O máximo do comprimento de onda de absorção e o tempo de vida para o seu estado excitado triplete são dependetes do solvente. Quando foram utilizados solventes doadores de hidrogênio, foi observado o surgimento de uma nova banda no espectro de absorção para os transientes, com máximo a $410 \mathrm{~nm}$, a qual foi atribuída ao radical cetila derivado da tioxantona. As constantes de velocidade de supressão para o triplete de tioxantona, $k_{q}$, variaram de $(1,7 \pm 0,1) \times 10^{6} \mathrm{~L} \mathrm{~mol}^{-1} \mathrm{~s}^{-1}$ para tolueno a $c a .10^{9} \mathrm{~L} \mathrm{~mol}^{-1} \mathrm{~s}^{-1}$ para fenol e seus derivados contendo substituintes poleres, bem como para indol, trietilamina e DABCO.
\end{abstract}

The photoreactivity of the triplet excited state of thioxanthone (TX) was investigated employing the laser flash photolysis technique. The wavelength for the absorption maximum and the lifetime of the triplet excited state are solvent dependent. When hydrogen donor solvents were employed, a new band at $410 \mathrm{~nm}$ was observed in the triplet absorption spectrum, which was attributed to the ketyl radical derived from thioxantone. Quenching rate constants, $k_{q}$, ranged from $(1.7 \pm 0.1) \times 10^{6} \mathrm{~L} \mathrm{~mol}^{-1} \mathrm{~s}^{-1}$ for toluene to $c a .10^{9} \mathrm{~L} \mathrm{~mol}^{-1} \mathrm{~s}^{-1}$ for phenol and its derivatives containing polar substituents, as well as for indole, triethylamine and DABCO.

Keywords: laser flash photolysis, tioxanthone, triplet excited state, solvent effect

\section{Introduction}

The photophysical and photochemical properties of several aromatic ketones are strongly influenced by the energy and configuration of their electronically excited state. ${ }^{1-4}$

The nature of the excited state of thioxathone (9H-thioxanthen-9-one, TX) and its derivatives has been amply studied. The singlet lowest excited state of TX has $\pi \pi^{*}$ configuration, being very fluorescent in hydroxylic solvents, with a triplet energy located at $65.5 \mathrm{kcal} \mathrm{mol}^{-1}{ }^{5,6}$ This efficiency for triplet formation is attributed to the transition involving $\mathrm{S}_{1}\left(\pi \pi^{*}\right) \rightarrow \mathrm{T}_{2}\left(\mathrm{n} \pi^{*}\right)$ states, followed by internal conversion $\mathrm{T}_{2} \rightarrow \mathrm{T}_{1}\left(\pi \pi^{*}\right){ }^{6} \mathrm{It}$ is well known that intersystem crossing processes involving inversion of configuration are 3 orders of magnitude

*e-mail: jcnetto@ufrrj.br more efficient than similar processes without change of configuration. ${ }^{7,8}$ Moreover, the proximity between its $\mathrm{T}_{1}$ and $\mathrm{T}_{2}$ triplet electronic states leads to photophysical properties that are strongly influenced by solvent effects and substitution on the aromatic ring. ${ }^{9,10}$ TX can easily form free radicals from the triplet excited state which permits its use as photoinitiator for polymerization ${ }^{11-13}$ and as a photosensitizer. ${ }^{14}$ In the presence of tertiary amines, the triplet excited state of TX produces an intermediate exciplex, through the involvement of an initial excited charge transfer complex. The exciplex decay leads to the formation of an ion-radical pair which ultimately can form the radical pair ketyl/alkylamino, as result of the hydrogen transfer from the amine radical cation to the thioxanthone anion radical (Scheme 1). The alkylamino radical is the effective initiator of polymerization. ${ }^{15}$

In this work the triplet reactivity of TX towards hydrogen and electron donors was investigated employing the laser flash photolysis technique (LFP). 


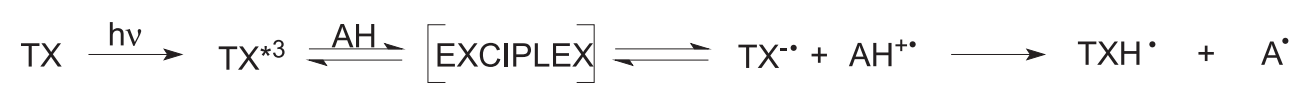

Scheme 1.

\section{Materials and Methods}

\section{Materials}

The solvents acetonitrile, carbon tetrachloride, dichloromethane, $n$-hexane, cyclohexane, toluene, methanol, ethanol and 2-propanol were from SigmaAldrich (spectroscopic grade). The reagents thioxanthone, trans-stilbene, 1-methylnaphthalene, 1,3-cyclohexadiene, 1,4-diazabicyclo [2.2.2] octane (DABCO), triethylamine (TEA), 1-hexene, 1-cyclohexene, 1-methyl-cyclopentene, 1,4-cyclohexadiene, indole, phenol, $p$-cyanophenol and $p$-methoxyphenol were from Sigma-Aldrich and used as received (purity $>99 \%$ ).

\section{Laser flash photolysis}

Nanosecond laser flash photolysis experiments were carried out at room temperature on deaerated acetonitrile solutions. The concentrations were adjusted to yield an absorbance of $c a .0 .3$ at the excitation wavelength $(355 \mathrm{~nm})$. Samples were contained in custom-built cells fabricated from $10 \mathrm{~mm} \times 10 \mathrm{~mm}$ rectangular Suprasil quartz tubes and were deaerated for at least $30 \mathrm{~min}$ with dry oxygen-free nitrogen. Stock solutions of quenchers, $10^{-2}-10^{-3} \mathrm{~mol} \mathrm{~L}^{-1}$, were prepared so that it was only necessary to add microliter volumes to the sample cell to reach appropriated quencher concentration. Samples were excited by the $3^{\text {rd }}$ harmonic $\left(\lambda_{\text {EXC }}=355 \mathrm{~nm}\right.$, single pulses of $10 \mathrm{~ns}$ duration and $40 \mathrm{~mJ} /$ pulse) of a pulsed Nd/YAG Surelite II. The LFP apparatus used was a LUZCHEM mini-system, model mLPF112. A 175W Xenon lamp was employed as detecting light source; the monochromator was a CUI laser Corporation Digikrön monochromator (model CM110), together with a Hamamatsu model R955 photomultiplier and a Tektronix TDS 2012 oscilloscope. The Tektronix oscilloscope signal was transferred to a personal computer for data storing and processing. Transient absorption spectra were recorded by time interval selection after the laser pulse (seven pulses at each wavelength, with an interval of ten nanometers).

\section{Results and Discussion}

Laser excitation $(355 \mathrm{~nm})$ of degassed thioxanthone solutions in several solvents leads to the formation of a transient which shows absorption maximum varying from
$640 \mathrm{~nm}\left(\mathrm{CCl}_{4}\right)$ to $583 \mathrm{~nm}\left(\mathrm{CH}_{3} \mathrm{OH}\right)$, depending on solvent polarity, as recently demonstrated by Ferreira et al. ${ }^{9}$ Similar dependency with the solvent polarity was found for the transient lifetime, which varies from $250 \mathrm{~ns}$ (toluene) to $10.5 \mu$ s (2-propanol). This species decays by first-order kinetics with some contribution from a second-order decay, which can be attributed to triplet-triplet annihilation, common in laser studies.

The transient absorption spectrum for thioxanthone in hydrogen-donor solvents, such as $n$-hexane, cyclohexane, toluene, methanol, ethanol or 2-propanol, shows a new species absorbing at $410 \mathrm{~nm}$, independently of the solvent nature (hydroxylic or non-hydroxylic) (Figure 1). This new species has been previously assigned to the ketyl radical derived from TX for the hydroxylic solvents methanol, ethanol and 2-propanol,, 916 with its formation occurring through a hydrogen abstraction reaction involving the triplet excited state of TX. These data are fully in accordance with previous results from the literature. ${ }^{17}$

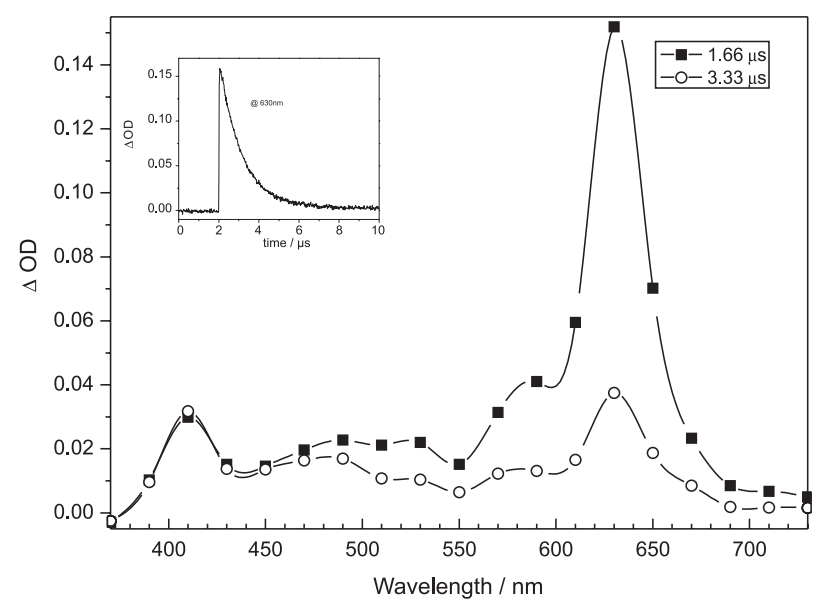

Figure 1. Transient absorption spectra obtained upon excitation on $355 \mathrm{~nm}$ of TX in cyclohexane, recorded at $1.66(\mathbf{\square})$ and $3.33 \mu \mathrm{s}(\mathrm{O})$ after the laser pulse. Inset: Decay for the transient generated upon excitation and monitored at $630 \mathrm{~nm}$.

Quenching experiments employing 1-methylnaphthalene $\left(\mathrm{E}_{\mathrm{T}}=60.6 \mathrm{kcal} \mathrm{mol}^{-1}\right), 1,3$-cyclohexadiene $\left(\mathrm{E}_{\mathrm{T}}=52.4 \mathrm{kcal}^{\mathrm{mol}}{ }^{-1}\right)$ and trans-stilbene $\left(\mathrm{E}_{\mathrm{T}}=49.3 \mathrm{kcal} \mathrm{mol}^{-1}\right),{ }^{18}$ in acetonitrile, revealed that the quenching rate constant in all cases is diffusion-controlled, which indicates the triplet nature of this transient (Table 1). Furthermore, the diffusion-control values for these quenching rate constants confirm that the triplet energy of TX is above $61 \mathrm{kcal} \mathrm{mol}^{-1}$. $^{10,19}$ 
Table 1. Second order quenching rate constants for thioxanthone triplet in acetonitrile

\begin{tabular}{ll}
\hline Quencher & $k_{q}\left(\mathrm{~L} \mathrm{~mol}^{-1} \mathrm{~s}^{-1}\right)$ \\
\hline trans-stilbene & $(3.9 \pm 0.2) \times 10^{10}$ \\
1-methylnaphthalene & $(1.2 \pm 0.1) \times 10^{10}$ \\
1,3-cyclohexadiene & $(2.0 \pm 0.1) \times 10^{10}$ \\
DABCO & $(5.4 \pm 0.4) \times 10^{9}$ \\
triethylamine & $(8.1 \pm 0.4) \times 10^{9}$ \\
methanol & $(2.0 \pm 0.1) \times 10^{5}$ \\
ethanol & $(3.1 \pm 0.1) \times 10^{5}$ \\
cyclohexane & $(5.9 \pm 0.2) \times 10^{5}$ \\
2-propanol & $(1.2 \pm 0.1) \times 10^{6}$ \\
toluene & $(1.7 \pm 0.1) \times 10^{6}$ \\
1-hexene & $(2.8 \pm 0.1) \times 10^{6}$ \\
1-cyclohexene & $(1.9 \pm 0.1) \times 10^{7}$ \\
1-methylcyclopentene & $(4.5 \pm 0.1) \times 10^{7}$ \\
1,4-cyclohexadiene & $(1.8 \pm 0.2) \times 10^{8}$ \\
phenol & $(1.8 \pm 0.1) \times 10^{9}$ \\
$p$-cyanophenol & $(4.3 \pm 0.3) \times 10^{9}$ \\
$p$-methoxyphenol & $(5.5 \pm 0.3) \times 10^{9}$ \\
indole & $(8.6 \pm 0.7) \times 10^{9}$ \\
\hline
\end{tabular}

The experimentally observed kinetic rate constant, $k_{\text {decay' }}$, is related to the quenching rate constant, $k_{\mathrm{q}}$, according to the equation below: ${ }^{20}$

$k_{\text {decay }}=k_{o}+k_{q}[Q]$

where $k_{o}$ is the triplet decay rate constant in the absence of quencher, $k_{q}$ is the triplet decay rate constant in the presence of the quencher and $[Q]$ is the quencher concentration. Linear Stern-Volmer plots for the quenching of TX triplet were obtained for all quenchers used and showed good correlation coefficients (Table 1 and Figure 2).

Rate constants for the quenching of thioxanthone triplet by simple olefins were also measured by laser flash photolysis, with the values obtained ranging from $(2.8 \pm 0.1) \times 10^{6} \mathrm{~L} \mathrm{~mol}^{-1} \mathrm{~s}^{-1}$ (1-hexene) to $(1.8 \pm 0.2) \times 10^{8} \mathrm{~L} \mathrm{~mol}^{-1} \mathrm{~s}^{-1}$ (1,4-cyclohexadiene). The transient absorption spectrum recorded after laser photolysis of TX, at an olefin concentration where the entire triplet signal disappeared, does not show the formation of any new transient. These hydrogen abstraction rate constants clearly follow the stability of the intermediate carbon-centered radical formed from the hydrogen donor, with the olefin containing a doubly allylic hydrogen, i.e., 1,4-cyclohexadiene being the most reactive (Table 1). ${ }^{21}$

Transient absorption spectra for thioxanthone in methanol, ethanol or 2-propanol are similar to that observed when 1,4-cyclohexadiene was employed as quencher. Thus, a weak absorption with maximum at $410 \mathrm{~nm}$ is readily observed, which can be assigned to the ketyl radical derived from thioxanthone. ${ }^{16}$ Quenching rate constants measured for these alcohols, in acetonitrile, are
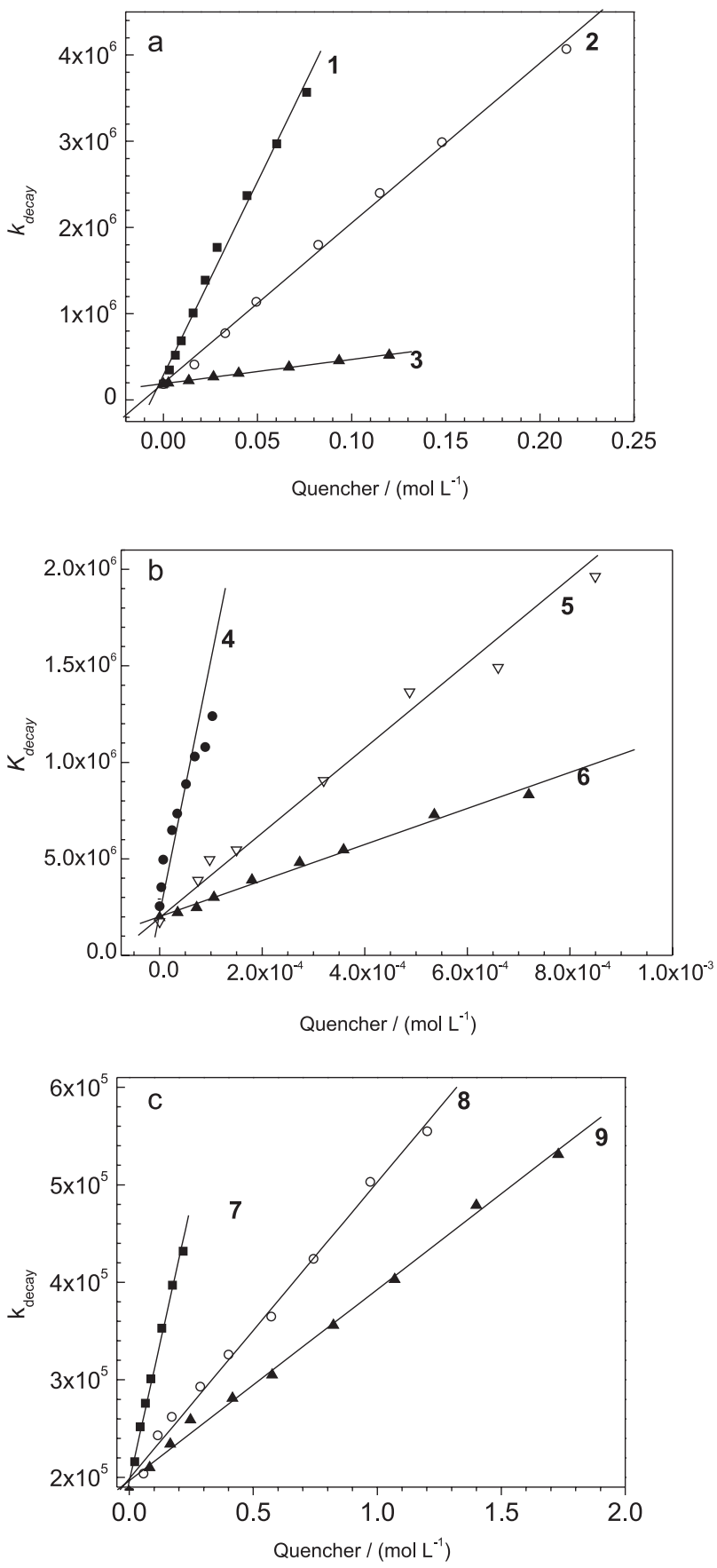

Figure 2. Stern-Volmer plots for the quenching of triplet TX in acetonitrile by (a) 1-methyl-cyclopentene, 1; cycloexene, 2; 1-hexene, 3; (b) indole, 4; phenol, 5; triethylamine, 6; (c) 2-propanol, 7; ethanol, 8; methanol, 9.

related to the stability of the ketyl radical derived from the alcohol and follow the order $\mathrm{k}_{\mathrm{q}(2-\text { propanol })}>\mathrm{k}_{\mathrm{q}(\text { ethanol })}>\mathrm{k}_{\mathrm{q}(\text { methanol })}$ (Table 1).

The high values for the quenching rate constants obtained for olefins and alcohols in acetonitrile, when compared to those obtained for other triplet ketones having $\mathrm{n} \pi *$ configuration, ${ }^{21}$ strongly suggest that the lowest triplet excited state of TX has $n \pi^{*}$ configuration in this 
solvent. This is fully in accord with a recent paper from Ferreira et al. ${ }^{9}$

An important difference between $n \pi^{*}$ and $\pi \pi^{*}$ states is that the oxygen atom in the carbonyl group is more electron deficient in the former than in the later. Thus, in the photoreduction process by different hydrogen donors, the $T_{1}\left(n \pi^{*}\right)$ state is more reactive than the $T_{1}\left(\pi \pi^{*}\right){ }^{22-24}$ Taking as an example the quenching rate constant, $\left.(1.8 \pm 0.2) \times 10^{8} \mathrm{~L} \mathrm{~mol}^{-1} \mathrm{~s}^{-1}\right)$, for the hydrogen abstraction from 1,4-cyclohexadiene (a very efficient hydrogen donor), one can observe that this value is remarkably fast and comparable to those obtained for typical $n \pi^{*}$ mono or diketones, such as benzophenone ${ }^{21}$ or 1,1,4,4-tetramethyl1,4-dihydro-2,3-naphthalenedione. ${ }^{25}$ For comparison, ketones such as dinaphthylketones, having lowest energy triplet with $\pi \pi^{*}$ character, show quenching rate constant by 1,4 -cyclohexadiene of $c a .10^{6} \mathrm{~L} \mathrm{~mol}^{-1} \mathrm{~s}^{-1}{ }^{26}$

Table 1 also shows quenching results employing hydrogen and electron donors in acetonitrile. The reactivity of triplet TX towards phenols is higher than for alcohols, olefins containing allylic hydrogen or aromatic compounds containing benzylic hydrogen, which is fully in accord with previous results from the literature. ${ }^{27}$ This is expected due to the lower bond dissociation energy of the $\mathrm{O}-\mathrm{H}$ bonding and the lower oxidation potential of phenols. In particular, the reaction with phenols is faster for lowest triplet excited state of ketones with charge transfer $\pi \pi^{*}$ character $\left(\pi \pi^{*}[\mathrm{CT}]\right)$ than for those with lowest $n \pi *$ triplet state. ${ }^{26,28}$ It has been suggested that for phenols the hydrogen transfer occurs through a mechanism involving the initial formation of an exciplex, resulting from a hydrogen bond interaction between the phenolic hydroxyl and the carbonyl group. It is proposed that the hydrogen transfer would occur in two steps: an initial electron-transfer, followed by an ultra-fast proton-transfer. ${ }^{10,27}$ This process results in the experimental observation of the ketyl/phenoxyl radical pair, as observed in the present work (Scheme 2 and Figure 3). The ketyl radical derived from TX can be observed at $410 \mathrm{~nm}$ after quenching by phenol, para-methoxyphenol and paracyanophenol (Figure 4). The weak absorption observed at $430 \mathrm{~nm}$ in this figure can be associated to the formation of the aryloxyl radical derived from para-cyanophenol. ${ }^{29}$
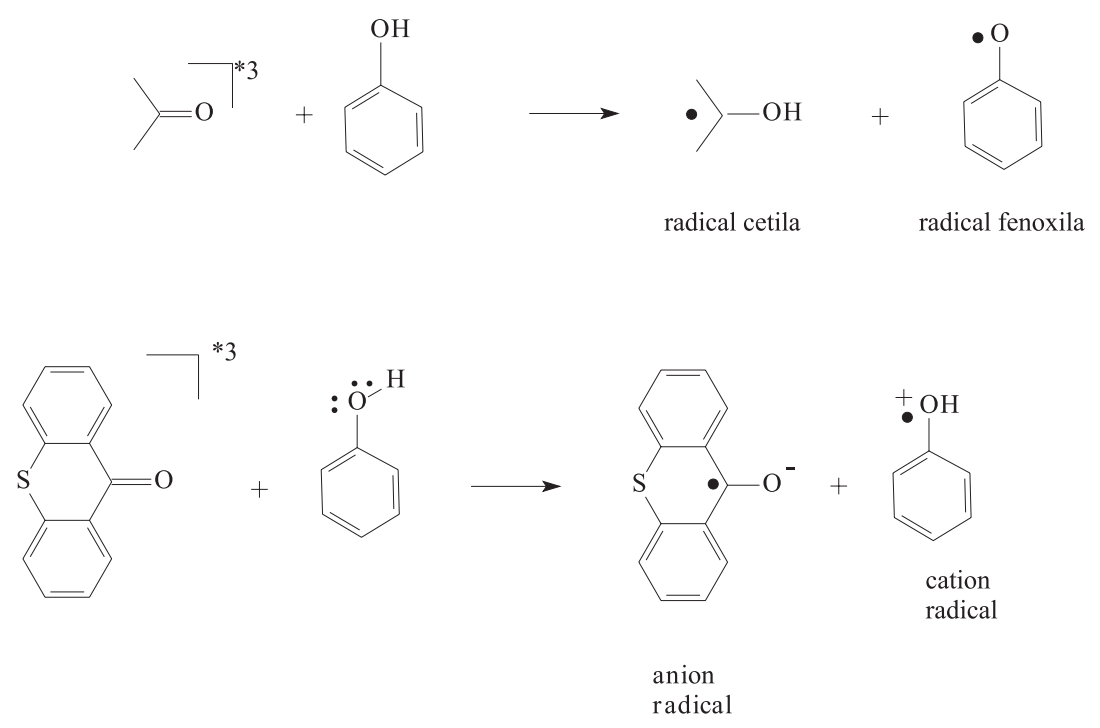

proton transfer

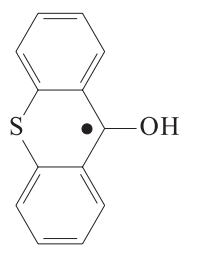

ketyl radical $\downarrow$

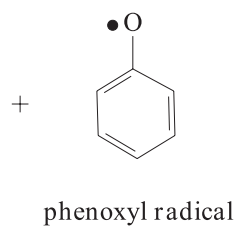

phenoxyl radical

Scheme 2. 


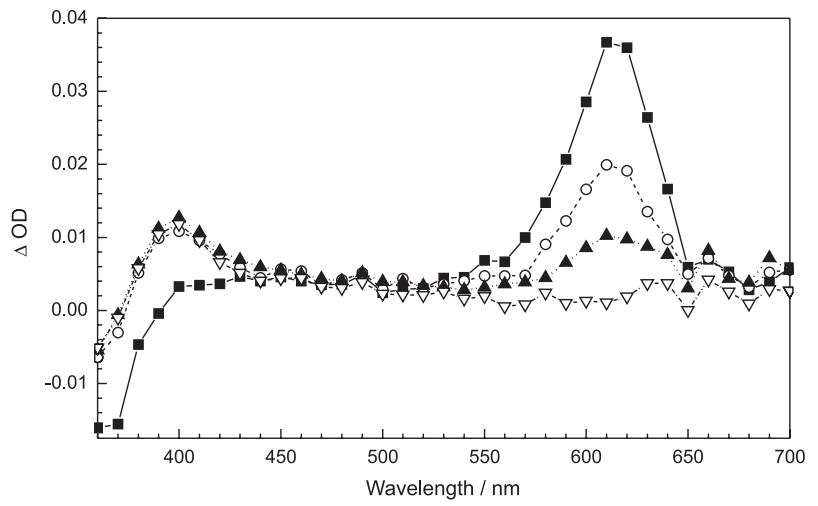

Figure 3. Transient absorption spectra obtained upon excitation at $355 \mathrm{~nm}$ of TX with $0.00031 \mathrm{~mol} \mathrm{~L}^{-1}$ of para-methoxyphenol in acetonitrile recorded at $0.27(\mathbf{\square}), 0.66(\bigcirc), 1.16(\mathbf{\Delta})$ and $4.65 \mu$ s $(\nabla)$ after the laser pulse.

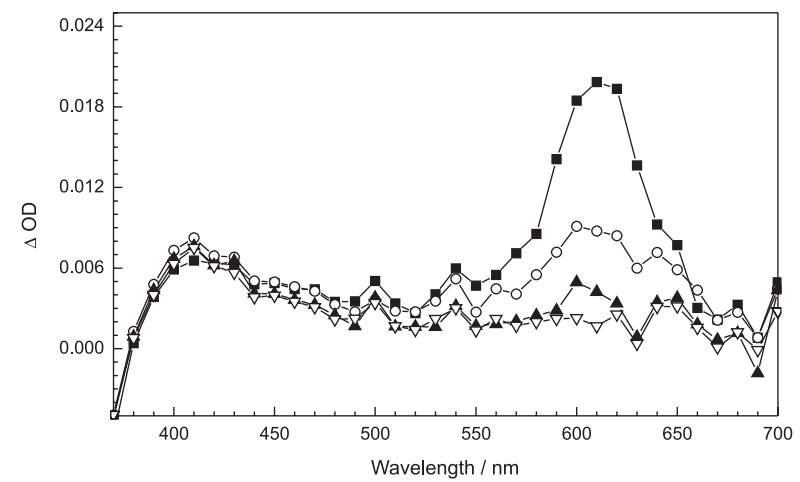

Figure 4. Transient absorption spectra obtained upon excitation on $355 \mathrm{~nm}$ of TX with $0.00025 \mathrm{~mol} \mathrm{~L}^{-1}$ of para-cyanophenol in acetonitrile recorded at $0.73(\mathbf{\square}), 1.69(\bigcirc), 2.64(\boldsymbol{\Delta})$ and $5.50 \mu \mathrm{s}(\nabla)$ after the laser pulse.

Analysis of the substituent effect on the quenching of TX triplet by phenol and derivatives showing polar substituents, such as para-methoxy and para-cyano, revealed that the presence of these substituents did not have a strong influence in the reaction from the TX triplet. This lack of dependence on polar substituents in the quenching reaction is an indication that the primary process involves a charge transfer complex, which results in an electron transfer, followed by a fast proton transfer, ultimately leading to the formation of the corresponding radical pair (Scheme 2). The configuration of the ketone lowest triplet excited state is considered to be a factor determining the smaller influence in the electron transfer-mediated reactions. ${ }^{10,22,30}$

The transient absorption spectrum observed upon laser irradiation of TX in the presence of indole show the disappearance of the absorption band at $610 \mathrm{~nm}$, corresponding to the triplet excited state of TX, and the formation of new bands at $410 \mathrm{~nm}$ (ketyl radical derived from TX) and $500 \mathrm{~nm}$ (indolyl radical) ${ }^{31}$ (Figure 5), with the quenching rate constant $(8.6 \pm 0.7) \times 10^{9} \mathrm{~L} \mathrm{~mol}^{-1} \mathrm{~s}^{-1}$ being compared to those obtained for phenols. This result indicates that the mechanism involved in the quenching

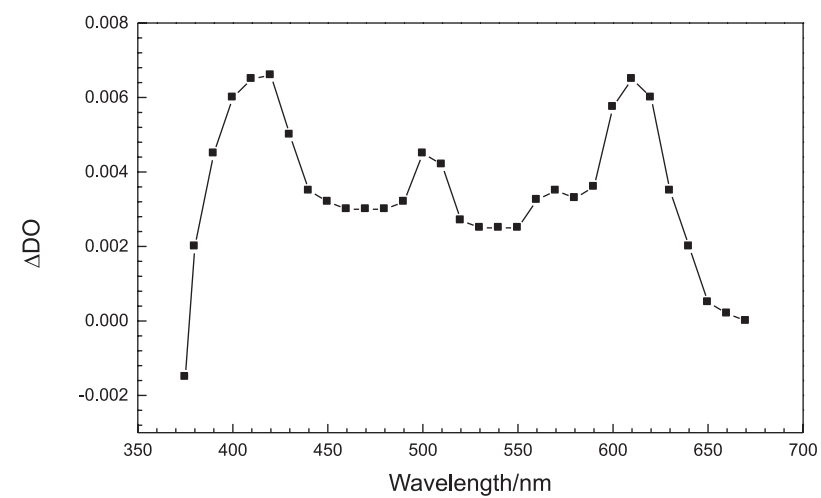

Figure 5. Transient absorption spectrum obtained upon excitation on $355 \mathrm{~nm}$ of TX with $0.0025 \mathrm{~mol} \mathrm{~L}^{-1}$ of indole in acetonitrile recorded at $1.80 \mu \mathrm{s}$ after the laser pulse.

process of triplet TX by this species must also involve an initial electron transfer followed by a fast proton transfer, as proposed for phenols. ${ }^{32}$

The transient absorption spectra obtained upon laser excitation of thioxanthone in the presence of the well known efficient electron donors TEA $\left(2.04 \times 10^{-4} \mathrm{~mol} \mathrm{~L}^{-1}\right)$ or $\operatorname{DABCO}\left(7.20 \times 10^{-4} \mathrm{~mol} \mathrm{~L}^{-1}\right)$, in acetonitrile, and recorded several microseconds after the laser pulse, show bands at $410 \mathrm{~nm}$ and in the $540-680 \mathrm{~nm}$ region. The transient observed at $410 \mathrm{~nm}$ can be assigned to the anion radical derived from thioxanthone (Figure 6). ${ }^{23}$ The quenching rate constants for the reaction of TX triplet with DABCO $(5.4 \pm 0.4) \times 10^{9} \mathrm{~L} \mathrm{~mol}^{-1} \mathrm{~s}^{-1}$ or TEA $(8.1 \pm 0.3) \times$ $10^{9} \mathrm{~L} \mathrm{~mol}^{-1} \mathrm{~s}^{-1}$, are in good accordance with a mechanism involving an electron transfer process.

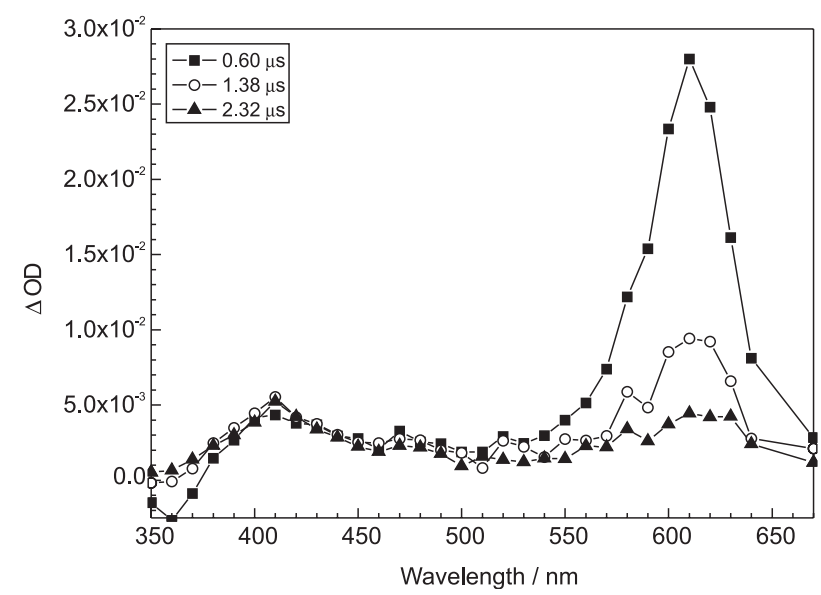

Figure 6. Transient absorption spectra obtained upon excitation on $355 \mathrm{~nm}$ of TX with $0.00017 \mathrm{~mol} \mathrm{~L}^{-1}$ of TEA in acetonitrile recorded at $0.60(\mathbf{\square})$, $1.38(\bigcirc)$ and $2.32 \mu \mathrm{s}(\boldsymbol{\Delta})$ after the laser pulse.

\section{Conclusion}

In conclusion, employing the laser flash photolysis technique it was observed that the triplet excited state of 
TX is easily obtained and dependent of the polarity and hydrogen bonding properties of the solvent. The triplet lifetime for TX increases with the change from non-polar to polar solvents, whereas its $\lambda_{\text {max }}$ for triplet-triplet absorption shows a blue shift as a function of solvent polarity. The confirmation of the triplet character of this transient was made by quenching experiments with very well known triplet quenchers such trans-stilbene, 1-methylnaphthalene and 1,3-cyclohexadiene, for which diffusion-controlled rate constants were obtained. The transient absorption spectrum in the presence of hydrogen donor solvents shows a weak band at $410 \mathrm{~nm}$, when compared to the strong triplet-triplet absorption. This same absorption at $410 \mathrm{~nm}$ is observed when quenching experiments were performed with hydrogendonor quenchers, which was attributed to the ketyl radical derived from thioxanthone. Similar values for the quenching rate constants were observed for DABCO, TEA, indole and phenols. For the later, there was no dependence of $k_{q}$ with para-substitution on the phenols, indicating a mechanism involving electron-transfer followed by a fast proton transfer.

\section{Acknowledgments}

Financial support from the Coordenação de Aperfeiçoamento do Pessoal de Nível Superior-Programa Nacional de Cooperação Acadêmica (CAPES-PROCAD, Brazil), Financiadora de Estudos e Projetos (FINEP) and Fundação de Amparo à Pesquisa do Estado da Bahia (FAPESB) are gratefully ackowledged. J. F. R. thanks the Conselho Nacional de Desenvolvimento Científico e Tecnológico (CNPq-Brazil) for a graduate fellowship. J. C. N.-F. thanks CNPq for a research fellowship. F. A. S. thanks CAPES, Programa de Pós-graduação em Química of the Instituto de Química, Universidade Federal da Bahia (UFBA) and Prof. Dr Cristina M. Quintella (LABLASERUFBA) for a Pos-Doctoral traineeship. We thank M.Sc. Eduardo Benes da Silva for assistance.

\section{References}

1. Morlet-Savary, F.; Ley, C.; Jacques, P.; Wieder, F.; Fouassier, J. P.; J. Photochem. Photobiol., A 1999, 126, 7.

2. Togashi, D. M.; Nicodem, D. E.; Spectrochim. Acta, Part A 2004, 60, 3205.

3. Silva, M. T.; Netto-Ferreira, J. C.; J. Photochem. Photobiol., A 2004, 162, 225.

4. Yamaji, M.; Aoyama, Y.; Furukawa, T.; Itoh, T.; Tobita, S.; Chem. Phys. Lett. 2006, 420, 187.

5. Dalton, J. C.; Turro, N. J.; J. Am. Chem. Soc. 1971, 93, 6230.

6. Dalton, J. C.; Montgomery, F. C.; J. Am. Chem. Soc. 1974, 96, 6230 .
7. El Sayed, M. A.; J. Phys. Chem. 1963, 38, 2834.

8. Azumi, T.; Chem. Phys. Lett. 1974, 25, 135.

9. Ferreira, G. C.; Schmitt, C. C.; Neumann, M. G.; J. Braz. Chem. Soc. 2006, 17, 905.

10. Lathioor, E. C.; Leigh, W.; Photochem. Photobiol. 2006, 82, 291.

11. Fouassier, J. P.; Jacques, P.; Lougnot, D. J.; Pilot, T.; Polymer Photochem. 1984, 5, 57.

12. Shah, M.; Allen, N. S.; Salleh, N. G.; Corrales, T.; Egde, M.; Catalina, F.; Bosch, P.; Green, A.; J. Photochem. Photobiol., A 1997, 111, 229.

13. Morita, H.; Shimizu, J.; J. Photopolym. Sci. Technol. 1989, 2 , 193.

14. Jockusch, S.; Timpe, H. J.; Schnabel, W.; Turro, N. J.; J. Phys. Chem. 1997, 101, 440.

15. Catalina, F.; Tercero, J. M.; Peinado, C.; Sastre, R.; Mateo, J. L.; J. Photochem. Photobiol., A 1989, 50, 249.

16. Allen, N. S.; Catalina, F.; Green, P. N.; Green, W. A.; Eur. Polym. J. 1986, 22, 347.

17. Allen, N. S.; Catalina, F.; Green, P. N.; Green, W. A.; Eur. Polym. J. 1986, 22, 871.

18. Murov, S. L.; Carmichael, I.; Hug, G. L.; Handbook of Photochemistry, $2^{\text {nd }}$ ed.; Marcel Dekker: New York, 1993.

19. Herkstroeter, W. G.; Lamola, A. A.; Hammond, G. S.; J. Am. Chem. Soc. 1964, 86, 4537.

20. Stern, O.; Volmer, M.; Physik. Z. 1919, 20, 183.

21. Encinas M. V.; Scaiano, J. C.; J. Am. Chem. Soc. 1981, 103, 6393.

22. Wagner, P. J.; Park, B.-S.; Org. Photochem. 1991, 11, 227.

23. Scaiano, J. C.; J. Photochem. 1973, 2, 81.

24. Wagner, P. J.; Kemppainen, A. E.; Schott, H. N.; J. Am. Chem. Soc. 1973, 95, 5604.

25. Scaiano, J. C.; Wintgens, V.; Netto-Ferreira, J. C.; J. Photochem. Photobiol., A 1989, 50, 707.

26. Jovanovic, S. V.; Morris, D. G.; Pliva, C. N.; Scaiano, J. C.; J. Photochem. Photobiol., A 1997, 107, 153.

27. Das, P. K.; Encinas, M. V.; Scaiano, J. C.; J. Am. Chem. Soc. 1981, 103, 4154.

28. Miranda, M. A.; Lahoz, A.; Matínez-Manez, R.; Boscá, F.; Castell, J. V.; Pérez-Prieto, J.; J. Am. Chem. Soc. 1999, 121, 11569.

29. Shuler, R. H.; Neta, P.; Zemel, H.; Fessenden, R. W.; J. Am. Chem. Soc. 1976, 98, 3825.

30. Aspari, P.; Ghoneim, N.; Haselbach, E.; vom Raumer, M.; Suppan, P.; Vauthey, E.; J. Chem. Soc., Faraday Trans. 1996, 92, 1689.

31. Merényi, G.; Lind, J.; Shen, X.; J. Phys. Chem. 1988, 92, 134.

32. Perez-Prieto, J.; Boscá, F.; Galian, R. E.; Lahoz, A.; Domingo, L. R.; Miranda, M. A.; J. Org. Chem. 2003, 68, 5105.

Received: March 15, 2009 Web Release Date: January 28, 2010 